\title{
Complications of the endovascular management of acute ischemic stroke
}

\author{
This article was published in the following Dove Press journal: \\ Vascular Health and Risk Management \\ 28 November 2014 \\ Number of times this article has been viewed
}

\section{Heather L Gill \\ Jeffrey J Siracuse \\ In-Kyong Parrack \\ Zhen S Huang \\ Andrew J Meltzer}

Division of Vascular and Endovascular Surgery, Weill Cornell Medical

College, New York, NY, USA
Correspondence: Andrew J Meltzer Division of Vascular and Endovascular Surgery, Weill Cornell Medical College, 525 East 68th Street, P 704, New York, NY 10065, USA

$\mathrm{Tel}+\mid$ 2I 274673 II

$\mathrm{Fax}+\mathrm{I} 2127365840$

Email ajm9007@med.cornell.edu

\begin{abstract}
Acute ischemic stroke is a significant source of morbidity and mortality across the globe. Currently, the only US Food and Drug Administration approved medical treatment of acute ischemic stroke is intravascular (IV) alteplase. While IV thrombolysis has been shown to decrease morbidity and mortality from acute ischemic stroke, it is limited in both its efficacy in certain types of stroke, as well as in its generalizability. It has been shown that time to revascularization is one of the most important predictors of outcomes in acute ischemic stroke, and thus clinicians have turned to endovascular options in efforts to improve outcomes from stroke. Direct intra-arterial thrombolysis was one of the first of such efforts to improve efficacy rates and increase the timeline for thrombolytic therapy. More recently, investigators and clinicians have turned to newer endovascular options in attempts to further improve recanalization rates. Many different endovascular techniques have been employed and are growing exponentially in use. Examples include stenting, as well as mechanical thrombectomy with both older-generation devices and newer stent retrieval technology. While the majority of the literature focuses on the effectiveness of different techniques, such as recanalization rates and major overall outcomes such as death and disability, there is very little literature on the complications of the different techniques. The purpose of this article is to review the different forms of endovascular treatment of acute ischemic stroke and their associated complications.
\end{abstract}

Keywords: alteplase, endovascular techniques, revascularization

\section{Introduction}

Acute ischemic stroke is a significant source of morbidity and mortality across the globe. ${ }^{1}$ In the United Kingdom, it is the leading cause of disability adjusted life years, and in the United States, it costs the health care system $\$ 36.5$ billion US each year. ${ }^{1,2}$ Currently, the only US Food and Drug Administration (FDA) approved medical treatment of acute ischemic stroke is intravascular (IV) alteplase (TPA). ${ }^{3}$ While IV thrombolysis has been shown to decrease morbidity and mortality from acute ischemic stroke, it is limited in both its efficacy in certain types of stroke, as well as in its generalizability. ${ }^{4}$ Even with the more recently expanded timeline for use, up to 4.5 hours after the initiation of symptoms, it is estimated that only about $1 \%-2 \%$ of all stroke victims are eligible for thrombolysis due to stringent contraindications. ${ }^{5,6}$ Of those who are eligible, approximately 5-15 patients need to be treated in order to help one patient. ${ }^{7}$ Given the serious risks associated with thrombolysis, it is far from a perfect therapy. In addition to timeline constraints, it has been shown that systemic thrombolysis has fairly poor outcomes in patients with total occlusions of certain cerebral vessels. ${ }^{8}$ Given these factors, and given that it has been shown that time to 
revascularization is one of the most important predictors of outcomes in acute ischemic stroke, clinicians have turned to endovascular options in efforts to improve outcomes from stroke. ${ }^{9}$ While the endovascular options actually take longer in some instances, it is thought that proper protocols and good technique and experience will improve both the time to patency and patency itself. Direct intra-arterial thrombolysis was one of the first of such efforts to improve efficacy rates and increase the timeline for thrombolytic therapy. ${ }^{10}$ It is currently in both the American Heart Association and European Stroke Organisation guidelines as an option in the treatment of acute stroke with middle cerebral artery occlusions. ${ }^{11,12}$ More recently, investigators and clinicians have turned to newer endovascular options in attempts to further improve recanalization rates. ${ }^{9}$ Many different endovascular techniques have been employed and are growing exponentially in use. ${ }^{13}$ While the majority of the literature focuses on the effectiveness of different techniques, such as recanalization rates and major overall outcomes such as death and disability, there is very little literature on the complications of the different techniques. The most commonly seen complications include acute bleed in the treated area, embolus to the nontreated area, vessel dissection or perforation, device fracture, and access complications. These complications can have wide ranging effects from asymptomatic findings to devastating neurologic outcomes. It is difficult to assess these complications, as most articles have different definitions and reporting standards for each of these potential problems. The purpose of this article is to review the different forms of endovascular treatment of acute ischemic stroke (stenting and first- and second-generation stent retrievers) and their associated complications in as much as they are reported. Bridging or combination therapy with intra-arterial lytic therapy (IA)/IV and the endovascular techniques will not be discussed.

\section{Stenting}

While stenting of the carotid artery plays a role in the treatment algorithm for ischemic stroke secondary to extracranial carotid disease, a thorough discussion of the role of carotid stenting (versus carotid endarterectomy or medical therapy) is beyond the scope of this review. In the acute setting, stenting of the extracranial carotid circulation may be necessary to deliver mechanical thrombectomy devices into the area of interest. This has been documented in many of the studies on older and newer generation thrombectomy devices, but it has not been investigated in terms of long-term complications. ${ }^{10-12}$ As such, although it certainly has potential serious complications, it will not be further discussed here. The use of stenting of intracranial vessels to reestablish patency and flow in a timely fashion is the primary use described when dealing with stenting for acute ischemic stroke. Stenting has the advantages of being highly successful at recanalizing vessels, and for reestablishing flow to the ischemic Penumbra quickly. However, it also carries significant risks such as stent occlusion, coverage of collateral vessels, and the need for dual antiplatelet therapy immediately postoperatively in the setting of acute stroke. At this point in time, the majority of the literature on stenting comes in the form of retrospective case series. ${ }^{14-18}$ The first reported use was in 2006 from Fitzsimmons et al, ${ }^{14}$ who reported a rescue use of a stent to revascularize a target vessel with good success and no complications. Since that time, the largest series come from Levy et al, Zaidat et al, and Linfante et al with 20 or fewer patients in each. ${ }^{15-18}$ These series report mortality rates of $26 \%-37 \%$ and symptomatic intracerebral hemorrhage rates of $0 \%-27 \%$. (see Table 1 ). Unfortunately, of all the case series reported to date, only two report on groin complications with rates of $5 \%-10 \%$, and only two others report on procedure-related adverse events such as embolization to a new or the same territory, as well as vessel dissection or vasospasm. ${ }^{16,18-20}$ Sauvageau et al ${ }^{21}$ report one instance of vessel perforation for a rate of $9 \%$, but the others do not mention this, and thus it is unclear if these complications did not occur, or if they were not investigated. Given the lack of reporting on any complications, it is hard to glean anything in terms of a safety profile from these few retrospective reports on stenting, other than the idea that it can potentially be used as a "bail out" option.

\section{Mechanical thrombectomy}

The next method of endovascular treatment of stroke investigated is that of mechanical thrombectomy. This treatment consists of mechanically removing the thrombus and thus reestablishing vessel patency. It can be broadly categorized into first-generation and second-generation devices. The two US FDA-approved first-generation devices are the Merci ${ }^{\circledR}$ Retrieval system (Stryker Neurovascular, Fremont, CA, USA) and the Penumbra device (Penumbra, Inc., Alameda, CA, USA). The Merci Retrieval system is a family of corkscrew-shaped devices consisting of flexible nitinol wire with coil loops, of regular or variable pitch, some with arcading filaments attached. Once deployed, it assumes its coiled shape to engage and extract the clot. The Merci device was initially investigated in two initial trials (Merci Stroke Trial and the Multi Merci Trial) and has subsequently been compared to other devices in dedicated trials 


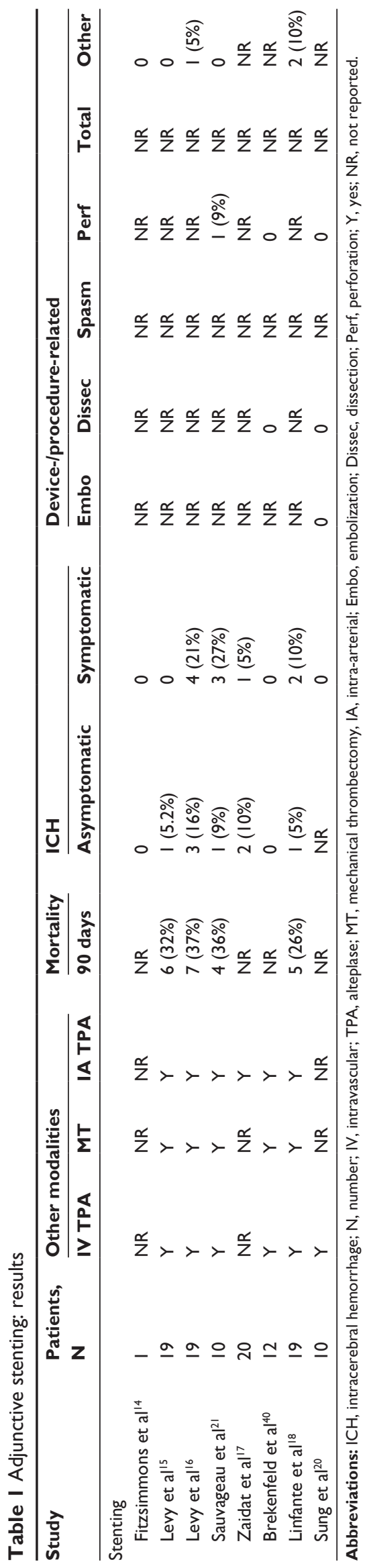

(SWIFT and TREVO 2 trials), as well as in combination with other devices against thrombolysis in newer trials (the RECANALISE, IMS 3, and Rescue MR trials). ${ }^{22-29}$ Across the trials and series available (see Table 2), the patients being treated with the Merci device have a $23 \%-44 \%$ mortality rate, as well as rates of symptomatic and asymptomatic hemorrhage of $8 \%-10 \%$ and $27 \%-53 \%$, respectively. These trials, while still significantly lacking, are some of the best at reporting actual procedure-related complications and they report $1 \%-10 \%$ rates of groin complications, embolization, vessel dissection, and perforation. They show between $6 \%-33 \%$ of device-/procedure-related complications when reported. The Penumbra device is used for thrombus debulking and aspiration followed by direct thrombus removal if necessary. This device has also been investigated in initial series and trials (Penumbra Stroke Trial), as well in comparison trials to other devices, and as part of the previously mentioned larger broader endovascular versus thrombolysis trials. ${ }^{30-34}$ With the exception of small case series, the Penumbra device has been shown to have mortality rates of $14 \%-33 \%$, and symptomatic and asymptomatic hemorrhage rates of $6 \%-11 \%$ and $10 \%-17 \%$, respectively. This device is less well studied than the Merci device, and the trials and series have less clear reporting of complications. What has been reported are rates of device-/procedure-related complications in the range of $12 \%-15 \%$, with rates of embolization, dissection, and perforation in the range of $1 \%-5 \% .{ }^{30-34}$

As these first-generation embolectomy devices were being studied and evaluated after their US FDA approvals, newer techniques were being developed that would eventually prove to be more effective at recanalizing vessels with shorter operative times and fewer complications. ${ }^{24,25}$ These are the stent retrieval systems. There are many different systems; those studied the most are the Solitaire ${ }^{\mathrm{TM}}$ Flow Restoration device (ev3 Neurovascular, Inc., Plymouth, MN, USA), the Trevo ${ }^{\circledR}$ device (Stryker Neurovascular), and pREset (phenox GmbH, Bochum, Germany). These are self-expanding stent retrieval systems designed to restore blood flow in patients with ischemic stroke due to large intracranial vessel occlusion. When the stent is deployed within the target clot in the occluded vessel, the stent struts entrap the thrombus. When the stent is withdrawn in its unfolded state, the enmeshed thrombus is concurrently extracted from the vessel. Stent retrievals have the advantage of quick and easy restoration of blood flow to a desired vessel without the side effects of permanent stenting. These devices have been studied mostly in case series, single-arm trials, and in newer trials comparing 


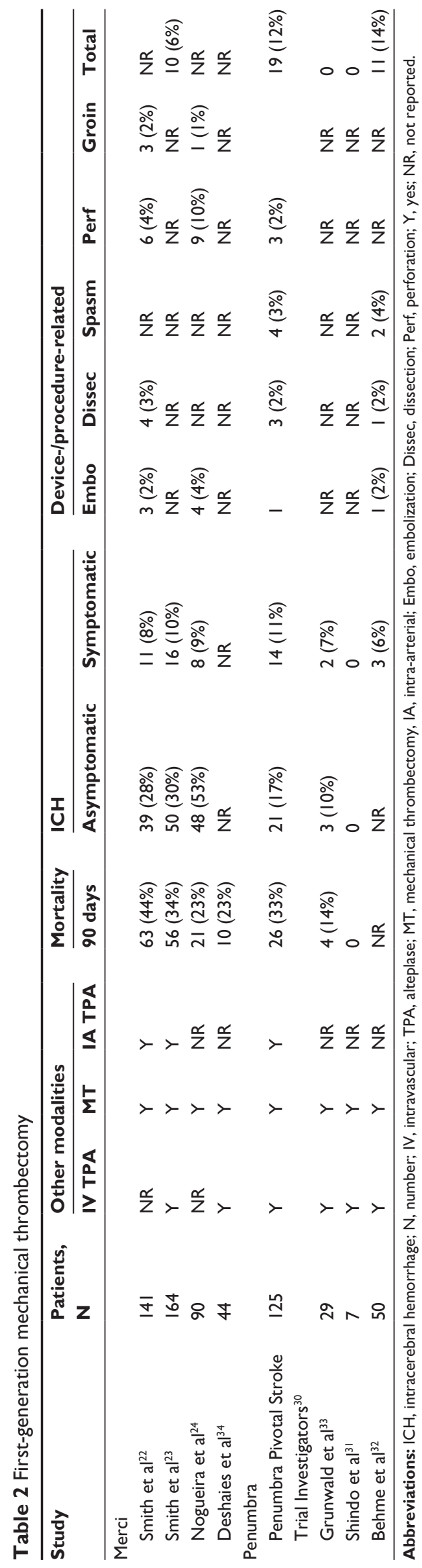

them to first-generation embolectomy devices. ${ }^{24,32,35-49}$ Because these are the newest technology, there are many case series and many poorly reported cohort studies (see Table 3 ). Some of the best series and studies come from Pereira et al, Dávalos et al for Solitaire, Noguiera et al and San Román et al for Trevo, and Kurre et al for pREset..$^{24,46,48-50}$ When put together, these major series and trials show mortality rates of $7 \%-28 \%$ with symptomatic and asymptomatic hemorrhage rates of $1 \%-5 \%$ and $7 \%-30 \%$, respectively. Total procedure-related complication rates varied widely (due to their definition and reporting) from $0 \%-20 \%$, and rates of embolization, dissection, and perforation, when reported, fell in the range of $1 \%-6 \%$.

\section{Limitation of the literature/ interpreting the literature}

The existing literature remains somewhat problematic. Firstly, most of the published literature is composed of small case series, retrospective reviews, and only a few randomized trials, many of which are inherently flawed. One of the major problems associated with this is that while there are generalized guidelines for the acute management of stroke, every center has different protocols and there appear to be deviations from these protocols a significant proportion of the time, even within the same institution. For instance, in almost every study on the endovascular treatment of stroke, a significant proportion of the patients received IV TPA ahead of time, or they were taken for treatment because of a failure of IV TPA. ${ }^{22-26}$ This leads to confusing results and different patient cohorts, making comparisons somewhat meaningless. Secondly, once the patient is on the table, even within the randomized trial, the principal interventionist would deviate in terms of the devices used and the methods employed and, thus, most of the reports have patients who underwent multiple and different endovascular techniques, again making the literature on complications hard to interpret. ${ }^{30-33}$ Another difficulty with the data is that there is very little consensus on the reporting of outcomes and complications. The definitions of procedurerelated adverse events, device-related adverse events, and symptomatic and asymptomatic hemorrhage all vary within each study. Compounding this is the fact that many of the reports do not discuss complications at all, or they discuss them selectively. In addition, the effects of the complications are almost never discussed. In the smaller case reports, it is often feasible to tease out what the effect was, but in the larger series and in the randomized trials while the complications are mentioned, they are rarely parsed out into symptomatic and asymptomatic. As well, it is often unclear if the poor outcomes 


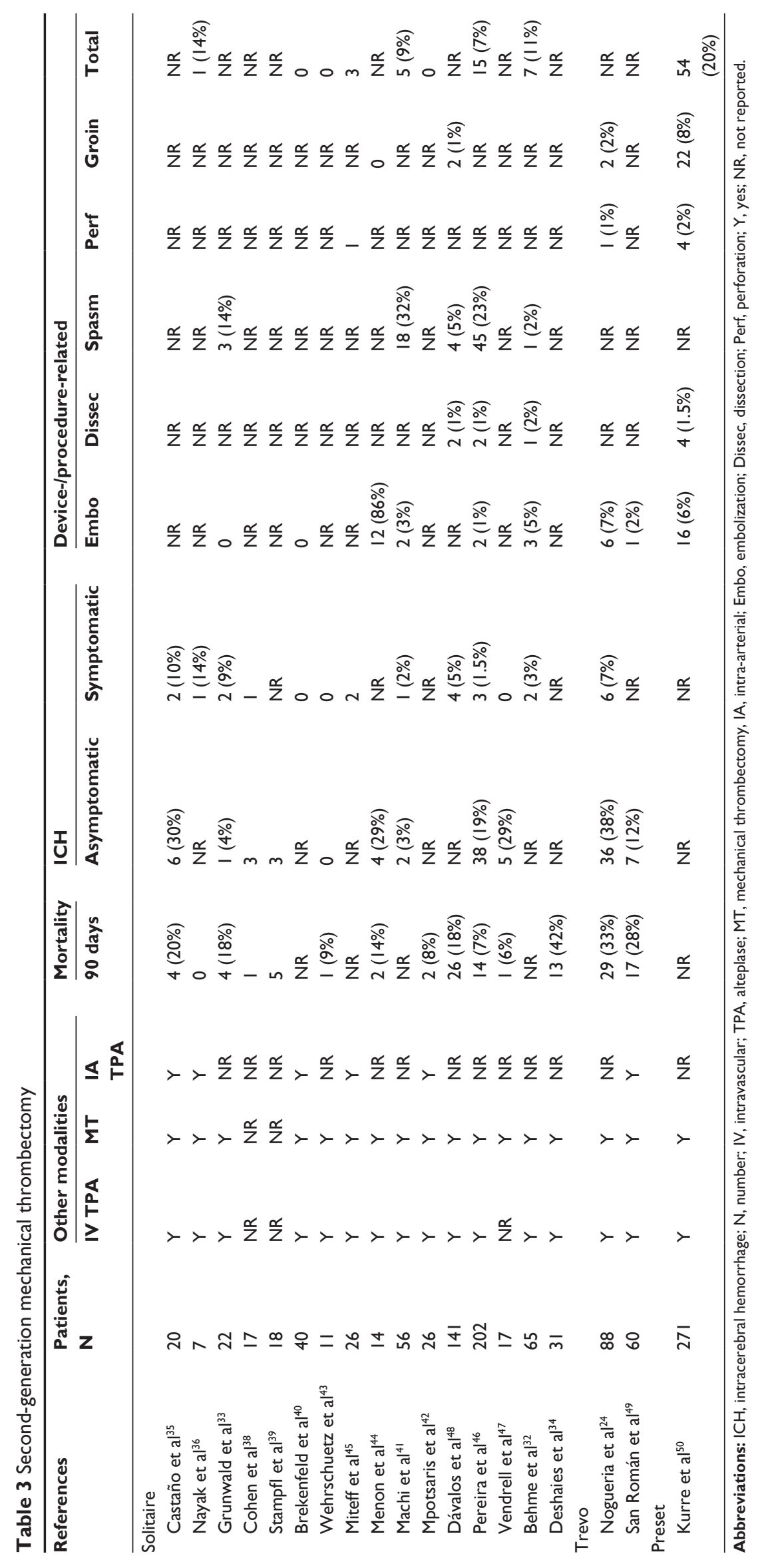


were indeed related to the treatment or the disease process. Going forward, in order to fully understand the advantages and limitations of each method, it will be important to focus not just on the revascularization rates and overall outcomes, but also on the procedure- and device-related complications.

\section{Future directions}

Recently, three randomized controlled trials were simultaneously released that demonstrated no benefit of endovascular therapy over IV TPA. ${ }^{26-28}$ Of these, there were two small studies and one large study that stopped early; none of them had good reporting of complications in either group beyond hemorrhage and death. These studies have been widely criticized for not including patients treated with the newer generation of mechanical thrombectomy devices which, in limited smaller studies, have been shown to be more effective at revascularization and possibly have fewer complications. ${ }^{24,25}$ Because of this fact, there is likely to be an ongoing role for endovascular therapy in the future, and it is imperative that future studies make a more determined effort to document not only recanalization and survival rates, but also all possible complications.

\section{Disclosure}

The authors report no conflicts of interest in this work.

\section{References}

1. World Health Organization [webpage on the Internet]. The atlas of heart disease and stroke. Geneva, Switzerland: World Health Organization; 2014. Available from: http://www.who.int/cardiovascular_diseases/ resources/atlas/en/. Accessed August 15, 2014.

2. Go AS, Mozaffarian D, Roger VL, et al; American Heart Association Statistics Committee and Stroke Statistics Subcommittee. Executive summary: heart disease and stroke statistics - 2014 update: a report from the American Heart Association. Circulation. 2014;129(3):399-410.

3. Jauch EC, Saver JL, Adams HP, et al; American Heart Association Stroke Council; Council on Cardiovascular Nursing; Council on Peripheral Vascular Disease; Council on Clinical Cardiology. Guidelines for the early management of patients with acute ischemic stroke: a guideline for healthcare professionals from the American Heart Association/American Stroke Association. Stroke. 2013;44(3):870-947.

4. Tissue plasminogen activator for acute ischemic stroke. The National Institute of Neurological Disorders and Stroke rt-PA Stroke Study Group. N Engl J Med. 1995;333(24):1581-1587.

5. Hacke W, Kaste M, Bluhmki E, et al; ECASS Investigators. Thrombolysis with alteplase 3 to 4.5 hours after acute ischemic stroke. $N$ Engl J Med. 2008;359(13):1317-1329.

6. Bluhmki E, Chamorro A, Dávalos A, et al. Stroke treatment with alteplase given 3.0-4.5 h after onset of acute ischaemic stroke (ECASS III): additional outcomes and subgroup analysis of a randomised controlled trial. Lancet Neurol. 2009;8(12):1095-1102.

7. Lees KR, Bluhmki E, von Kummer R, et al; ECASS, ATLANTIS, NINDS and EPITHET rt-PA Study Group. Time to treatment with intravenous alteplase and outcome in stroke: an updated pooled analysis of ECASS, ATLANTIS, NINDS, and EPITHET trials. Lancet. 2010;375(9727):1695-1703.
8. Tomsick T, Broderick J, Carrozella J, et al; Interventional Management of Stroke II Investigators. Revascularization results in the Interventional Management of Stroke II trial. AJNR Am J Neuroradiol. 2008;29(3): 582-587.

9. Rha JH, Saver JL. The impact of recanalization on ischemic stroke outcome: a meta-analysis. Stroke. 2007;38(3):967-973.

10. Furlan A, Higashida R, Wechsler L, et al. Intra-arterial prourokinase for acute ischemic stroke. The PROACT II study: a randomized controlled trial. Prolyse in Acute Cerebral Thromboembolism. JAMA. 1999;282(21):2003-2011.

11. Ringelstein EB, Chamorro A, Kaste M, et al; ESO Stroke Unit Certification Committee. European Stroke Organisation recommendations to establish a stroke unit and stroke center. Stroke. 2013;44(3): 828-840.

12. Kernan WN, Ovbiagele B, Black HR, et al; American Heart Association Stroke Council, Council on Cardiovascular and Stroke Nursing, Council on Clinical Cardiology, and Council on Peripheral Vascular Disease. Guidelines for the prevention of stroke in patients with stroke and transient ischemic attack: a guideline for healthcare professionals from the American Heart Association/American Stroke Association. Stroke. 2014;45(7):2160-2236.

13. Hassan AE, Chaudhry SA, Grigoryan M, Tekle WG, Qureshi AI. National trends in utilization and outcomes of endovascular treatment of acute ischemic stroke patients in the mechanical thrombectomy era. Stroke. 2012;43(11):3012-3017.

14. Fitzsimmons BF, Becske T, Nelson PK. Rapid stent-supported revascularization in acute ischemic stroke. AJNR Am J Neuroradiol. 2006;27(5):1132-1134.

15. Levy EI, Ecker RD, Horowitz MB, et al. Stent-assisted intracranial recanalization for acute stroke: early results. Neurosurgery. 2006;58(3):458-463; discussion 458-463.

16. Levy EI, Mehta R, Gupta R, et al. Self-expanding stents for recanalization of acute cerebrovascular occlusions. AJNR Am J Neuroradiol. 2007;28(5):816-822.

17. Zaidat OO, Wolfe T, Hussain SI, et al. Interventional acute ischemic stroke therapy with intracranial self-expanding stent. Stroke. 2008;39(8):2392-2395.

18. Linfante I, Samaniego EA, Geisbüsch P, Dabus G. Self-expandable stents in the treatment of acute ischemic stroke refractory to current thrombectomy devices. Stroke. 2011;42(9):2636-2638.

19. Brekenfeld C, Schroth G, Mattle HP, et al. Stent placement in acute cerebral artery occlusion: use of a self-expandable intracranial stent for acute stroke treatment. Stroke. 2009;40(3):847-852.

20. Sung SM, Lee TH, Lee SW, Cho HJ, Park KH, Jung DS. Emergent intracranial stenting for acute M2 occlusion of middle cerebral artery. Clin Neurol Neurosurg. 2014;119:110-115.

21. Sauvageau E, Samuelson RM, Levy EI, Jeziorski AM, Mehta RA, Hopkins LN. Middle cerebral artery stenting for acute ischemic stroke after unsuccessful Merci retrieval. Neurosurgery. 2007;60(4):701-706; discussion 706.

22. Smith WS, Sung G, Starkman S, et al; MERCI Trial Investigators. Safety and efficacy of mechanical embolectomy in acute ischemic stroke: results of the MERCI trial. Stroke. 2005;36(7):1432-1438.

23. Smith WS, Sung G, Saver J, et al; Multi MERCI Investigators. Mechanical thrombectomy for acute ischemic stroke: final results of the Multi MERCI trial. Stroke. 2008;39(4):1205-1212.

24. Nogueira RG, Lutsep HL, Gupta R, et al; TREVO 2 Trialists. Trevo versus Merci retrievers for thrombectomy revascularisation of large vessel occlusions in acute ischaemic stroke (TREVO 2): a randomised trial. Lancet. 2012;380(9849):1231-1240.

25. Saver JL, Jahan R, Levy EI, et al; SWIFT Trialists. Solitaire flow restoration device versus the Merci Retriever in patients with acute ischaemic stroke (SWIFT): a randomised, parallel-group, non-inferiority trial. Lancet. 2012;380(9849):1241-1249.

26. Ciccone A, Valvassori L, Nichelatti M, et al; SYNTHESIS Expansion Investigators. Endovascular treatment for acute ischemic stroke. $N$ Engl J Med. 2013;368(10):904-913. 
27. Kidwell CS, Jahan R, Gornbein J, et al; MR RESCUE Investigators. A trial of imaging selection and endovascular treatment for ischemic stroke. N Engl J Med. 2013;368(10):914-923.

28. Broderick JP, Palesch YY, Demchuk AM, et al; Interventional Management of Stroke (IMS) III Investigators. Endovascular therapy after intravenous t-PA versus t-PA alone for stroke. $N \mathrm{Engl} \mathrm{J} \mathrm{Med}$. 2013;368(10):893-903.

29. Mazighi M, Serfaty JM, Labreuche J, et al; RECANALISE investigators. Comparison of intravenous alteplase with a combined intravenousendovascular approach in patients with stroke and confirmed arterial occlusion (RECANALISE study): a prospective cohort study. Lancet Neurol. 2009;8(9):802-809.

30. Penumbra Pivotal Stroke Trial Investigators. The penumbra pivotal stroke trial: safety and effectiveness of a new generation of mechanical devices for clot removal in intracranial large vessel occlusive disease. Stroke. 2009;40(8):2761-2768.

31. Shindo A, Kawanishi M, Kawakita K, et al. Treatment of acute cerebral artery occlusion using the penumbra system: our early experience. Neurol Med Chir (Tokyo). 2014;54(6):441-449.

32. Behme D, Gondecki L, Fiethen S, Kowoll A, Mpotsaris A, Weber W. Complications of mechanical thrombectomy for acute ischemic stroke-a retrospective single-center study of 176 consecutive cases. Neuroradiology. 2014;56(6):467-476.

33. Grunwald IQ, Walter S, Papanagiotou P, et al. Revascularization in acute ischaemic stroke using the penumbra system: the first single center experience. Eur J Neurol. 2009;16(11):1210-1216.

34. Deshaies EM, Singla A, Villwock MR, Padalino DJ, Sharma S, Swarnkar A. Early experience with stent retrievers and comparison with previous-generation mechanical thrombectomy devices for acute ischemic stroke. J Neurosurg. 2014;121(1):12-17.

35. Castaño C, Dorado L, Guerrero C, et al. Mechanical thrombectomy with the Solitaire AB device in large artery occlusions of the anterior circulation: a pilot study. Stroke. 2010;41(8):1836-1840.

36. Nayak S, Ladurner G, Killer M. Treatment of acute middle cerebral artery occlusion with a Solitaire AB stent: preliminary experience. Br J Radiol. 2010;83(996):1017-1022.

37. Roth C, Papanagiotou P, Behnke S, et al. Stent-assisted mechanical recanalization for treatment of acute intracerebral artery occlusions. Stroke. 2010;41(11):2559-2567.

38. Cohen JE, Gomori JM, Leker RR, Moscovici S, Ramirez-Denoriega F, Itshayek E. Recanalization with stent-based mechanical thrombectomy in anterior circulation major ischemic stroke. J Clin Neurosci. 2012;19(1):39-43.
39. Stampfl S, Hartmann M, Ringleb PA, Haehnel S, Bendszus M, Rohde S Stent placement for flow restoration in acute ischemic stroke: a single-center experience with the Solitaire stent system. AJNR Am J Neuroradiol. 2011;32(7):1245-1248.

40. Brekenfeld C, Schroth G, Mordasini P, et al. Impact of retrievable stents on acute ischemic stroke treatment. AJNR Am J Neuroradiol. 2011;32(7):1269-1273.

41. Machi P, Costalat V, Lobotesis K, et al. Solitaire FR thrombectomy system: immediate results in 56 consecutive acute ischemic stroke patients. J Neurointerv Surg. 2012;4(1):62-66.

42. Mpotsaris A, Bussmeyer M, Loehr C, Oelerich M, Buchner H, Weber W. Mechanical thrombectomy in severe acute stroke: preliminary results of the Solitaire stent. J Neurol Neurosurg Psychiatry. 2012;83(1):117-118.

43. Wehrschuetz M, Wehrschuetz E, Augustin M, Niederkorn K, Deutschmann H, Ebner F. Early single center experience with the solitaire thrombectomy device for the treatment of acute ischemic stroke. Interv Neuroradiol. 2011;17(2):235-240.

44. Menon BK, Kochar P, Ah-Seng A, et al. Initial experience with a selfexpanding retrievable stent for recanalization of large vessel occlusions in acute ischemic stroke. Neuroradiology. 2012;54(2):147-154.

45. Miteff F, Faulder KC, Goh AC, Steinfort BS, Sue C, Harrington TJ. Mechanical thrombectomy with a self-expanding retrievable intracranial stent (Solitaire AB): experience in 26 patients with acute cerebral artery occlusion. AJNR Am J Neuroradiol. 2011;32(6):1078-1081.

46. Pereira VM, Gralla J, Davalos A, et al. Prospective, multicenter, singlearm study of mechanical thrombectomy using Solitaire Flow Restoration in acute ischemic stroke. Stroke. 2013;44(10):2802-2807.

47. Vendrell JF, Mernes R, Nagot N, et al. Evaluation of an intravenousendovascular strategy in patients with acute proximal middle cerebral artery occlusion. AJNR Am J Neuroradiol. 2013;34(3): 603-608.

48. Dávalos A, Pereira VM, Chapot R, Bonafé A, Andersson T, Gralla J; Solitaire Group. Retrospective multicenter study of Solitaire FR for revascularization in the treatment of acute ischemic stroke. Stroke. 2012;43(10):2699-2705.

49. San Román L, Obach V, Blasco J, et al. Single-center experience of cerebral artery thrombectomy using the TREVO device in 60 patients with acute ischemic stroke. Stroke. 2012;43(6):1657-1659.

50. Kurre W, Aguilar-Pérez M, Schmid E, Sperber W, Bäzner H, Henkes H. Clinical experience with the pREset stent retriever for the treatment of acute ischemic stroke - a review of 271 consecutive cases. Neuroradiology. 2014;56(5):397-403.
Vascular Health and Risk Management

\section{Publish your work in this journal}

Vascular Health and Risk Management is an international, peerreviewed journal of therapeutics and risk management, focusing on concise rapid reporting of clinical studies on the processes involved in the maintenance of vascular health; the monitoring, prevention and treatment of vascular disease and its sequelae; and the involvement of

\section{Dovepress}

metabolic disorders, particularly diabetes. This journal is indexed on PubMed Central and MedLine. The manuscript management system is completely online and includes a very quick and fair peer-review system, which is all easy to use. Visit http://www.dovepress.com/ testimonials.php to read real quotes from published authors. 